\title{
Near ideal electrical switching in fast ion conducting glasses: Evidence for an electronic process with chemical origin
}

\author{
B VAIDHYANATHAN, S ASOKAN ${ }^{\dagger}$ and $K$ J RAO* \\ Solid State and Structural Chemistry Unit, 'Instrumentation and Services Unit, Indian \\ Institute of Science, Bangalore 560012, India
}

MS received 25 May 1995

\begin{abstract}
Bulk Agl based fast ion conducting (FIC) glasses have been prepared by a novel microwave technique. Electrical switching characteristics of these glasses have been investigated for the first time. It has been found that AgI based FIC glasses exhibit a currentcontrolled high speed memory electrical switching behaviour. SEM, EDAX and ESR investigations have been performed on the virgin and switched sampies to understand the nature of the conducting state. A chemical model is proposed to explain the switching behaviour of these glasses, which is consistent with the observed results.
\end{abstract}

Keywords. Electrical switching; fast ion conducting glasses.

There has been a tremendous interest in silver ion conducting glasses because of their ability to show relatively high ionic conductivities at room temperature. These glasses also have other merits such as homogeneity, absence of grain boundaries, ease of preparation, diversity of composition and transparency. The earlier investigations on silver ion conducting glasses, are focussed mainly on the ionic transport and structure (Minami et al 1977; Kawamura and Shimoji 1986; Tatsumisago et al 1991). Also, the reported applications of these materials are mostly directed towards their use as electrolytes in solid state batteries of low energy density. Recently, the possibility of applications of AgI based fast ion conducting glasses as ambient temperature oxygen sensors, electron beam recording materials, etc has been explored (Kuwano 1990). In the present work, $\mathrm{AgI}-\mathrm{Ag}_{2} \mathrm{O}-\mathrm{MoO}_{3}\left(\mathrm{WO}_{3}\right)$ glasses have been prepared by a simple and fast microwave irradiation method. Electrical switching studies have been carried out, to find out the possibility of using these glasses in memory devices.

Bulk AgI- $\mathrm{Ag}_{2} \mathrm{O}-\mathrm{MoO}_{3}\left(\mathrm{WO}_{3}\right)(50: 25: 25)$ glasses have been prepared using a domestic microwave oven, operating at $2450 \mathrm{MHz}$ with a continuous power level of $980 \mathrm{~W}$ maximum. Appropriate amounts of analar grade reagents (in powder form), having a batch weight of $6 \mathrm{~g}$, were mixed thoroughly and placed inside the oven in a silica crucible. A homogeneous melt of the material, obtained in just about $5 \mathrm{~min}$, was quenched (quenching rate $\approx 10^{3} \mathrm{~K} / \mathrm{sec}$ ) between polished quartz plates. The rapid time scales involved in this preparation avoids the reduction of $\mathrm{Ag}^{+}$to $\mathrm{Ag}^{\mathbf{0}}$, encountered normally in conventional methods. Since the melt do not couple to microwave field as effectively as the initial charge containing AgI, the temperature of the melt does not raise further as rapidly as that of the initial mixture (Vaidhyanathan et al 1994). Yellow, transparent glasses obtained in the above manner were confirmed to be amorphous by X-ray diffraction (no sharp diffraction peaks) and glassy by differential scanning calorimetry (the glass transition temperature $\left(T_{\mathrm{g}}\right)$ is $348 \mathrm{~K}$ for molybdate glass and $419 \mathrm{~K}$ for tungstate glass).

${ }^{*}$ Corresponding author 
The electrical switching behaviour of $\mathrm{AgI}-\mathrm{Ag}_{2} \mathrm{O}-\mathrm{MoO}_{3}\left(\mathrm{WO}_{3}\right)(50: 25: 25)$ glasses was studied in a custom built PC based system (Chatterjee et al 1994a). Samples mechanically polished to different thicknesses, were mounted in a spring loaded cell between a point contact top electrode (cathode) and a fiat plate bottom electrode made of brass. A programmable, constant direct current $(0-50 \mathrm{~mA})$ was passed through the sample and the voltage developed across was measured.

The current-voltage characteristic of $\mathrm{AgI}-\mathrm{Ag}_{2} \mathrm{O}-\mathrm{MoO}_{3}\left(\mathrm{WO}_{3}\right)(50: 25: 25)$ glasses is shown in figure 1 . It is seen from figure 1 that with the increasing current, there is an initial ohmic increase in the voltage across the sample. At a threshold voltage, the sample suddenly switches to a low resistance state. Though the switching behaviour of $\mathrm{AgI}-\mathrm{Ag}_{2} \mathrm{O}-\mathrm{MoO}_{3}\left(\mathrm{WO}_{3}\right)(50: 25: 25)$ glasses is similar to that of chalcogenide glasses, it should be noted that the switching characteristic of $\mathrm{Agl}$ based samples is near ideal: Firstly, $\mathrm{AgI}-\mathrm{Ag}_{2} \mathrm{O}-\mathrm{MoO}_{3}\left(\mathrm{WO}_{3}\right)$ glasses do not show any significant non-linearity

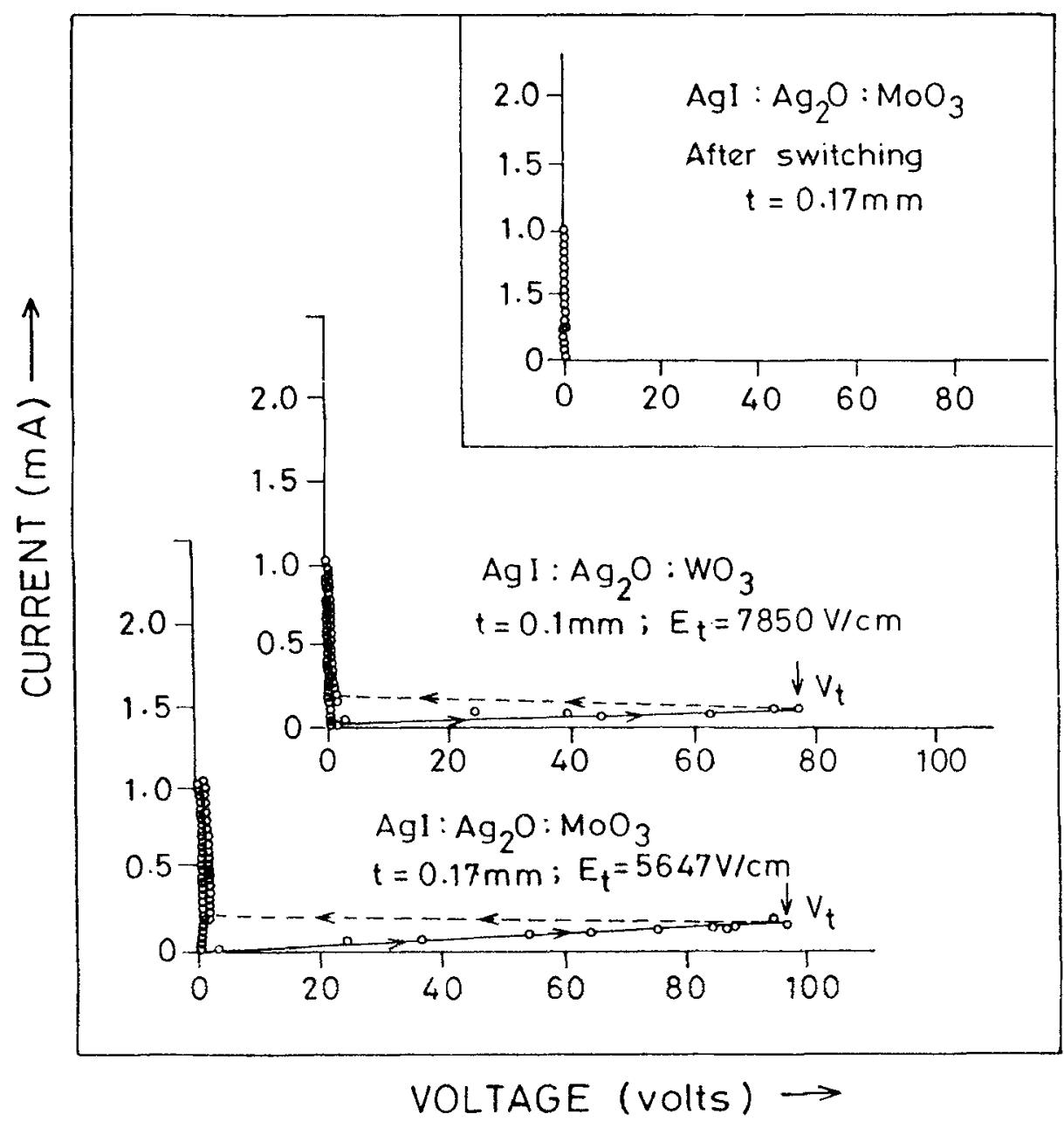

Figure 1. Electrical switching characteristics of $\mathrm{AgI}-\mathrm{Ag}_{2} \mathrm{O}-\mathrm{MoO}$ and $\mathrm{AgI}-\mathrm{Ag}_{2} \mathrm{O}-\mathrm{WO}_{3}$ glasses. The inset shows the $I-V$ behaviour of $\mathrm{AgI}-\mathrm{Ag}_{2} \mathrm{O}-\mathrm{MoO}_{3}$ glass after switching. 
near the switching threshold. Secondly, the samples switch very fast without exhibiting a stable negative resistance zone. Thirdly, the characteristic after switching is vertical indicating that the dynamic resistance is almost zero. Also the switching characteristics are found to be independent of the polarity. It is interesting to note that the switching in thesc samples can also be effected by a current sweep $(0-30 \mathrm{~mA})$ of $50 \mu \mathrm{sec}$ duration.

Due to experimental limitations it has not been possible to exactly determine the switching times of the samples studied. However, it is found with the available facilities that the switching time involved is around a $\mu \mathrm{sec}$.

The inset in figure 1 shows the $\mathrm{I}-\mathrm{V}$ characteristic of $\mathrm{AgI}-\mathrm{Ag}_{2} \mathrm{O}-\mathrm{MoO}_{3}$ sample, after the first switching cycle, indicating that the material is permanently latched in its low resistance state. Unlike many chalcogenide glasses (Chatterjee et al 1994b), the AgI based fast ion conducting glasses once switched are not brought back to the initial high resistance state by the application of resetting (large) current pulse. The switching experiments undertaken on different samples of the same thickness and composition reveal that the threshold voltage is highly reproducible within $\pm 2 \mathrm{~V}$. Figure 2 shows the variation of the threshold fields $\left(E_{\mathrm{r}}\right)$ of $\mathrm{AgI}-\mathrm{Ag}_{2} \mathrm{O}-\mathrm{MoO}_{3}\left(\mathrm{WO}_{3}\right)$ glasses as a function of sample thickness. It can be seen that $E_{t}$ increases linearly with the decrease in thickness, as in the case of many chalcogenide glasses (Adler 1971). It has also been found that for a given thickness $\mathrm{AgI}-\mathrm{Ag}_{2} \mathrm{O}-\mathrm{WO}_{3}$ samples have a slightly higher switching field compared to $\mathrm{AgI}-\mathrm{Ag}_{2} \mathrm{O}-\mathrm{MoO}_{3}$ samples.

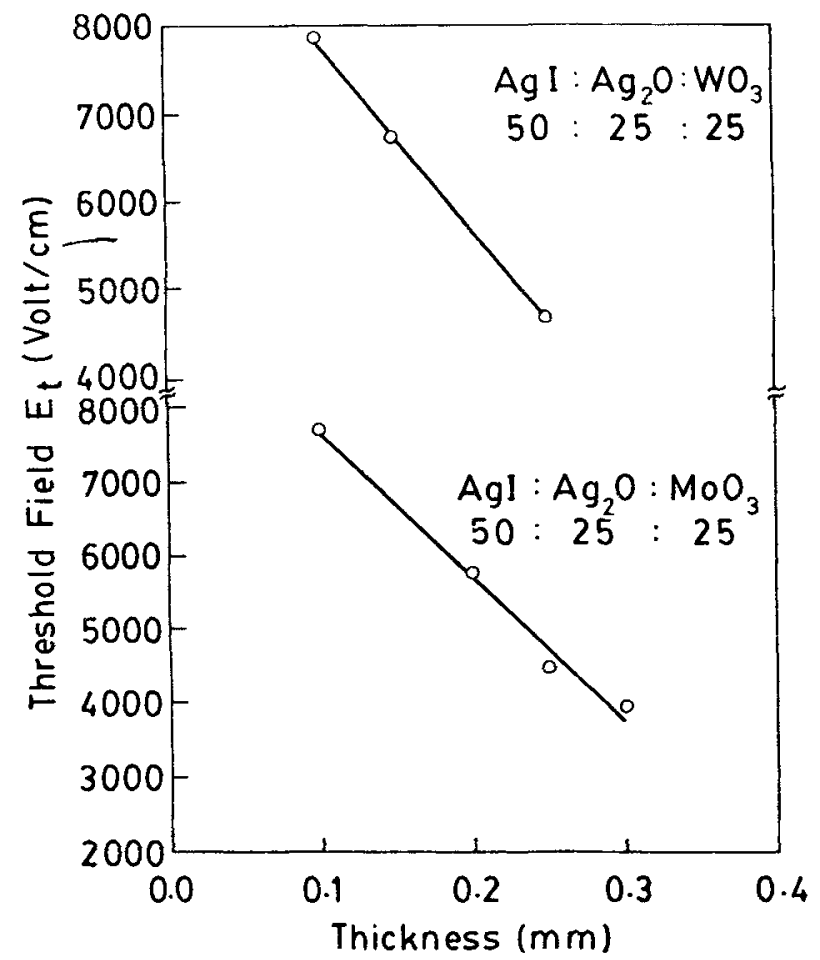

Figure 2. Thickness dependence of the threshold field of $\mathrm{AgI}-\mathrm{Ag}_{2} \mathrm{O}-\mathrm{MoO}_{3}$ and $\mathrm{AgI}-$ $\mathrm{Ag}_{2} \mathrm{O}-\mathrm{WO}_{3}$ glasses. 

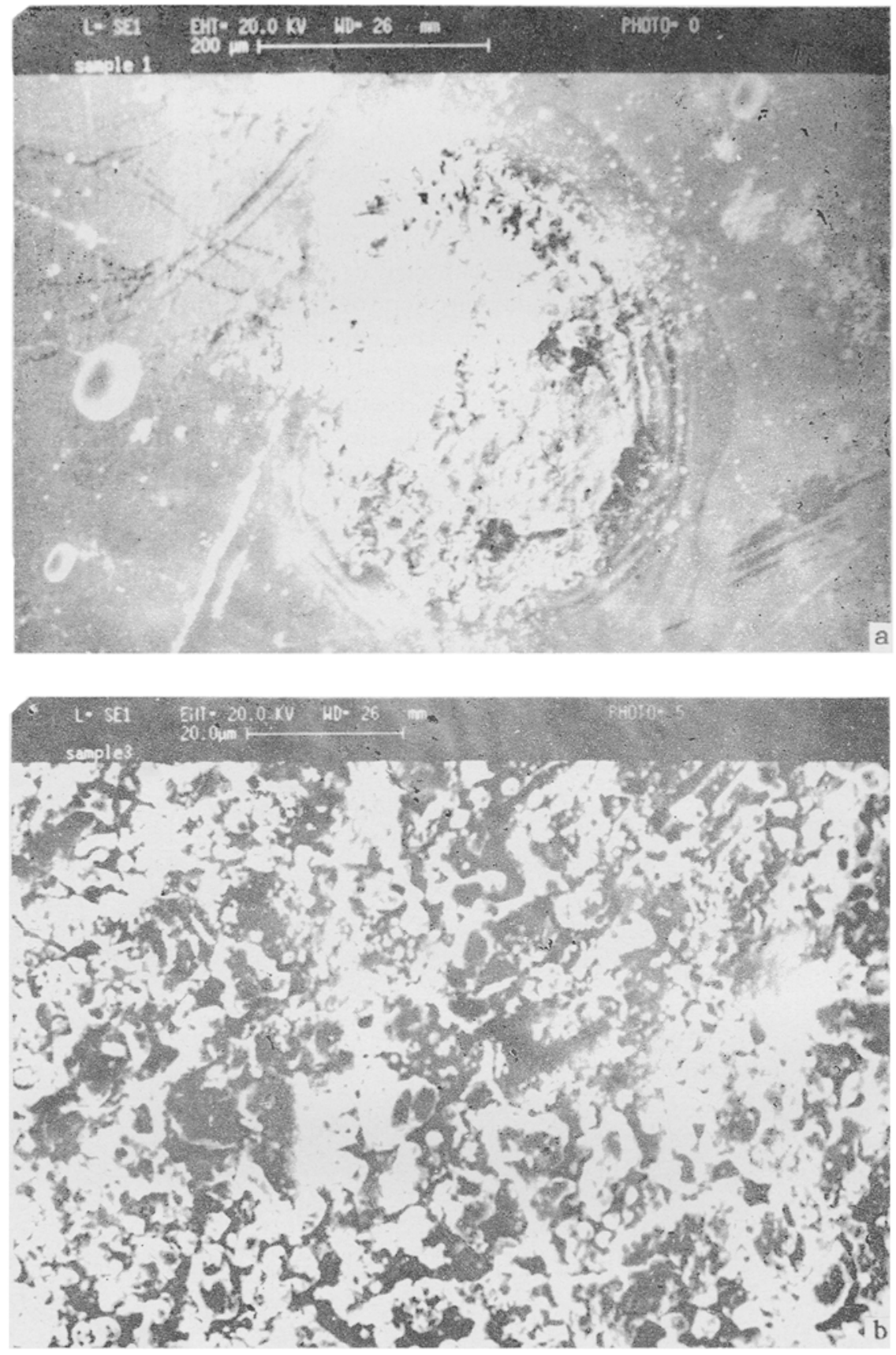

Figure 3. a. SEM photograph of $\mathrm{Agl}-\mathrm{Ag}_{2} \mathrm{O}-\mathrm{MOO}_{3}$ sample after switching showing the switched (central region) and the unswitched portions and $b$. SEM photograph of the switched zone of $\mathrm{AgI}-\mathrm{Ag}_{2} \mathrm{O}-\mathrm{MoO}_{3}$ sample. 
Electron microscopic and EDAX investigations have been carried out on the switched $\mathrm{AgI}-\mathrm{Ag}_{2} \mathrm{O}-\mathrm{MoO}_{3}$ samples. Figures 3(a) and 3(b) show the SEM pictures of $\mathrm{AgI}-\mathrm{Ag}_{2} \mathrm{O}-\mathrm{MoO}_{3}$ sample taken after switching. These electron micrographs reveal that the switched region between the top electrode and the bottom plate differ markedly from the bulk of the material. Composition analysis (EDAX) of the switched portion and the surrounding bulk indicates that there is a depletion of silver concentration and an enhancement of molybdenum in the switched zone (see table 1). The switched region also appears darker in colour compared to the unswitched surroundings. There was no detectable crystallization observed in the X-ray diffractogram of the switched sample.

Electron spin resonance (ESR) spectra of the two regions of $\mathrm{AgI}-\mathrm{Ag}_{2} \mathrm{O}-\mathrm{MoO}_{3}$ samples were examined. Interestingly it was found that the ESR trace of molybdenum in the virgin and the switched samples differed markedly (figure 4). The splitting reveals that $\mathrm{Mo}^{5+}$ is present in different structural configurations $\left(\mathrm{Mo}^{5+}\right.$ is always present in very low amounts - a few ppm-in molybdate glasses and give rise to ESR spectrum). There is also an enhancement of the ESR signal although we could not quantify the extent of enhanced reduction of $\mathrm{Mo}^{6+} \rightarrow \mathrm{Mo}^{5+}$.

The switching seems to be associated with (i) depletion of $\mathrm{Ag}$ and a corresponding increase in $\mathrm{Mo}$ in the switched region, (ii) reduction of $\mathrm{Mo}^{6+}$ to $\mathrm{Mo}^{5+}$ in addition to the reduction of $\mathrm{Ag}^{+}$to $\mathrm{Ag}^{0}$ at the electrode. The electrolyzed silver possibly gets deposited on the cathode as indicated by the tarnishing of the cathode. While the reduction of $\mathrm{Ag}^{+}$to $\mathrm{Ag}^{0}$ occurs at the cathode, $\mathrm{Mo}^{6+}$ to $\mathrm{Mo}^{5+}$ appears to be a chemical response to the anodic process, where it is easy to visualize loss of oxygen. In this connection we note that $\mathrm{Mo}^{5+}$ itself is more stable in an octahedral environment than in tetrahedral environment as shown elsewhere (Selvaraj and Rao 1985). Considering together the above observations we tentatively favour the following as the most probable mechanism: (i) at the cathode $\mathrm{Ag}^{+} \rightarrow \mathrm{Ag}^{\circ}$ and (ii) at the anode successive reactions take place as follows: (a) $\left[\mathrm{MoO}_{4}\right]^{2-} \rightarrow\left[\mathrm{MoO}_{4}\right]^{0}+2 e^{-}$, (b) $\left[\mathrm{MoO}_{4}\right]^{0} \rightarrow \mathrm{MoO}_{3}+1 / 2 \mathrm{O}_{2}$, (c) $\mathrm{MoO}_{3}+\left[\mathrm{MoO}_{4}\right]^{2-} \rightarrow 2\left[\mathrm{MoO}_{5 / 2} \mathrm{O}\right]^{1-}$ and (d) $2\left[\mathrm{Mo}^{6+} \mathrm{O}_{5 / 2} \mathrm{O}\right]^{1-} \rightarrow 2\left[\mathrm{Mo}^{5+} \mathrm{O}_{6 / 2}\right]^{1-}+1 / 2 \mathrm{O}_{2}$.

Thus the net process involves transport of two electrons in the external circuit and transfer of two electrons $\left(2 \mathrm{Mo}^{6+} \rightarrow 2 \mathrm{Mo}^{5+}\right)$ in the chemistry driven reduction of $\mathrm{Mo}^{6+}$ to $\mathrm{Mo}^{5+}$. The $d$ orbitals of $\mathrm{Mo}^{5+}$ in an octahedral field are split into $t_{2 \mathrm{~g}}$ and $e_{\mathrm{g}}$ set and the $t_{2 \mathrm{~g}}(4 d)$ with the $5 s$ and $5 p$ orbitals constitute the six bonding orbitals overlapping with the $p$ (or $s p^{\mathrm{n}}$ ] orbitals of the oxygen. The $e_{\mathrm{g}}$ orbitals $\left(d_{\mathrm{z}^{2}}\right.$ and $d_{\mathrm{x}^{2}-\mathrm{y}^{2}}$ ) of Mo now possess one electron (the degeneracy is lifted by Jahn-Teller distortion in

Table 1. Compositional analysis of the switched and the unswitched regions of the $\mathrm{AgI}-\mathrm{Ag}_{2} \mathrm{O}-\mathrm{MoO}_{3}$ sample.

\begin{tabular}{lcc}
\hline & \multicolumn{2}{c}{ Atomic $(\%)$} \\
\cline { 2 - 3 } Element & Unswitched zone & Switched zone \\
\hline Ag & 56 & 38 \\
Mo & 18 & 28 \\
I & 26 & 34
\end{tabular}




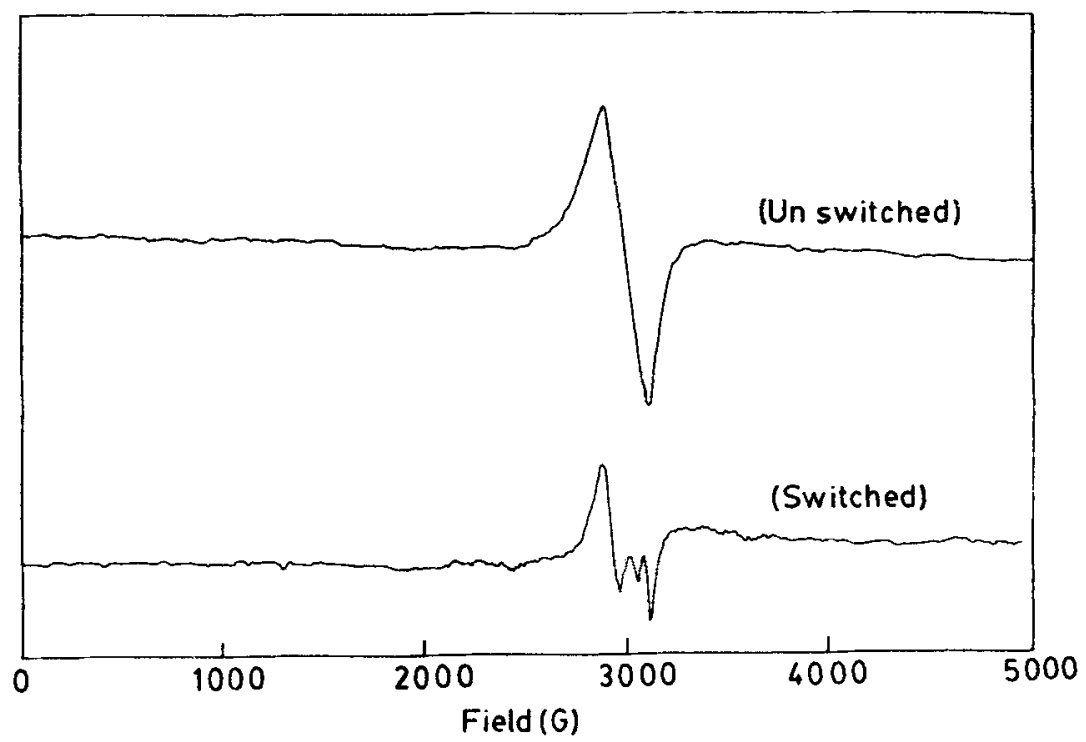

Figure 4. The ESR spectra of the virgin and switched $\mathrm{AgI}-\mathrm{Ag}_{2} \mathrm{O}-\mathrm{MoO}_{3}$ samples taken at $300 \mathrm{~K}$.

isolated $\left[\mathrm{Mo}^{5+} \mathrm{O}_{6 / 2}\right]^{1-}$ units). When an extensive chain of these units is formed between the electrodes it results in the formation of an $e_{\mathrm{g}}$ band and can easily provide a 'metallic' path (partially filled band) for electron transport. The observed switching is likely to be a consequence of this. It is emphasized that the initial reduction of $\mathrm{Ag}^{+}$to $\mathrm{Ag}^{0}$ at the electrode triggers the reduction of $\mathrm{Mo}^{6+}$ to $\mathrm{Mo}^{5+}$ in the glass. The change is irreversible in the experiment since both $\mathrm{Ag}$ and $\mathrm{O}$ are lost. The anodic reduction can proceed either with a single electron transfer or twoelectron transfer and the stages of anodic processes cannot be established without that knowledge. However $\mathrm{Mo}^{6+}$ to $\mathrm{Mo}^{5+}$ reduction is ultimately driven by chemical and stability considerations.

Structural change of tetrahedrally coordinated $\mathrm{Mo}^{6+}$ to octahedrally coordinated $\mathrm{Mo}^{5+}$ is only incidental. Because, we should expect reduction of $\mathrm{Ag}^{+}$to drive a reduction of anionic species and if there is an energetically accessible empty orbital which can form a partially filled band, a similar switching should be expected to occur. In borates and germanates we expect the empty $p$ (or $s p^{3}$ ) orbital of boron or the antibonding $d^{2} s p^{3}$ orbitals of Ge to constitute conduction bands which host the electron added during reduction. Indeed we observed sudden switching in these glasses also.

There is a difference in the switching voltages of molybdate and tungstate glasses; the latter switches at higher voltages. It may be due to the higher enthalpy of reduction for $\mathrm{W}^{6+} \rightarrow \mathrm{W}^{5+}$ (in oxides) than $\mathrm{Mo}^{6+} \rightarrow \mathrm{Mo}^{5+}$.

Interestingly it is found that the electrical switching fields of the samples studied are almost independent of temperature (ambient to $T_{\mathrm{g}}$ ) (Vaidhyanathan et al 1995). This observation confirms that the sharp permanent switching in AgI based fast ion conducting glasses is electronic, non-thermal in nature, corroborating the proposed chemical model. 
The thickness dependence of the switching voltage is however unclear at this stage. We tentatively attribute it to the facility of oxygen transport away from the region of electrical field between electrodes, in the case of thick samples. Thus the threshold field drops in thicker samples.

It will be interesting to study the effect of electrode material and geometry on the switching characteristics, the conductance ratio of the switched and unswitched regions of the material, etc. These investigations form the basis for future work.

We conclude that this novel electronic switching mode which leaves behind a permanent change in the glasses provides a new approach to designing memory switching materials.

\section{Acknowledgement}

The authors thank Mr S Prakash, Mr S Murugavel, Instrumentation and Services Unit and Mr A R Raju, Materials Research Centre for their help.

\section{References}

Adler D 1971 Amorphous semiconductors (London: CRC, Butterworths)

Chatterjee R, Acharya K V, Asokan S and Titus S S K 1994a Rev. Sci. Instrum. 652382

Chatterjee R, Asokan S and Titus S S K 1994b J. Phys. D. Appl. Phys. 272624

Kawamura J and Shimoji M $1986 \mathrm{~J}$. Non-cryst. Solids 88281

Kuwano J 1990 Solid State Ion. 40/41 696

Minami T, Nambu H and Tanaka M 1977 J. Am. Ceram. Soc. 60467

Selvaraj U and Rao K J 1985 J. Non-cryst. Solids 72315

Tatsumisago M, Shinkuma Y and Minami T 1991 Nature 354217

Vaidhyanathan B, Munia Ganguli and Rao K J 1994 J. Solid State Chem. 113448

Vaidhyanathan B. Rao K J, Prakash S, Murugavel S and Asokan S 1995 J. Appl. Phys. (in press) 